\title{
COMPOSIÇÃO QUÍMICA E PROTÉICO-MOLECULAR DA FARINHA DE RESÍDUOS DE CAMARÃO-SETE-BARBAS (Xiphopenaeus kroyeri)
}

\author{
ARLAN SILVA FREITAS * \\ ALEXANDRA BASÍLIO LOPES ** \\ MARÍLIA PENTEADO STEPHAN *** \\ FÉLIX EMÍLIO PRADO CORNEJO *** \\ ANGELA APARECIDA LEMOS FURTADO ***
}

\begin{abstract}
Caracterizou-se a farinha de resíduos de camarão-setebarbas quanto aos aspectos físico-químicos e análise molecular de proteínas. O corpo do camarão foi utilizado como parâmetro comparativo. Realizou-se estudo das proteínas pela quantificação de N-total, análise colorimétrica e avaliação molecular. Os resíduos apresentaram potencial em relação a dois nichos alimentares: nutricional (mineral) e dietético (alto teor de fibra alimentar e baixo conteúdo lipídico). Verificou-se neste resíduo baixo teor protéico solúvel pela extração e quantificação em método colorimétrico. Nos extratos analisados por eletroforese em gel de poliacrilamida contendo dodecil sulfato de sódio (SDS-PAGE) foi observada baixa diversidade protéica, devido ao menor número de cadeias polipeptídicas identificadas. A presença de uma banda de $74 \mathrm{kDa}$, resistente ao tratamento térmico, pode ser utilizada como marcador de padrão de identidade molecular desta farinha.
\end{abstract}

PALAVRAS-CHAVE: CAMARÃO-RESÍDUO; FARINHA-CAMARÃO; ELETROFORESE.

\section{INTRODUÇÃO}

A possibilidade do aproveitamento de resíduos de camarão (exoesqueleto, cefalotórax e telson/cauda), na forma de farinha, não deve ser descartada.

* $\quad$ Aluno de Pós-graduação, Universidade Federal Rural do Rio de Janeiro (UFRRJ), Instituto de Tecnologia, Pós-Graduação em Ciência e Tecnologia de Alimentos, Seropédica, RJ. (e-mail: arlanfreitas@yahoo.com.br).

** Estagiária, Escola Técnica Federal de Química, Rio de Janeiro, RJ. (e-mail alexandrabl@ig.com.br).

*** Pesquisadores, EMBRAPA Agroindústria de Alimentos, Rio de Janeiro, RJ. (e-mail: stephan@ctaa.embrapa.br). 
Seu baixo valor nutritivo, com enfoque protéico e a presença de teores consideráveis de cinzas $(40,00 \%)$ e fibras $\left(12,30 \mathrm{~g} \cdot \mathrm{kg}^{-1}\right)$, tem sido demonstrado mediante testes biológicos (SHAHIDI e SYNOWIECKI, 1991; FANIMO et al., 2000). EMOKPAE (1983) estudou a distribuição de massa em espécies de camarão e observou que $42,20 \%$ correspondiam à carne com a casca, 30,70\% à cabeça, 3,50\% ao exoesqueleto, $9,20 \%$ aos membros e cauda, e $4,70 \%$ ao intestino.

GILDBERG e STENBERG (2001) destacaram o alto teor de quitina em resíduos de camarão e descreveram procedimento técnico para extração deste polímero. FREITAS et al. (1976) mostraram que os resíduos constituem cerca de $55,40 \%$ do peso total do camarão, deduzindo que a quantidade desse material desperdiçado na cidade do Recife foi de $1.320,60$ t no ano de 1976. Relatam ainda a viabilidade de aproveitamento de 211,30 t de resíduos desidratados, ao tomar por base rendimento $16 \%$.

A técnica da eletroforese em gel de poliacrilamida tem sido utilizada amplamente em pesquisas de identificação de espécies de camarões cozidos e in natura (AN et al., 1989), detecção de adulteração em carne de camarão (CRAIG et al., 1995) e determinação do peso molecular de quitinases na farinha de camarão e de caranguejo (WANG e HWANG, 2001). A eletroforese em gel de poliacrilamida contendo dodecil sulfato de sódio (SDS-PAGE) constitui método eficaz de separação dos componentes moleculares em mistura protéica.

Este trabalho teve por objetivo avaliar a composição físico-química e protéico-molecular de resíduos de camarão, pelo método de eletroforese, sendo usado o corpo do camarão in natura como modelo comparativo.

\section{MATERIAL E MÉTODOS}

\subsection{MATERIAL}

Camarão-sete-barbas (Xiphopenaeus kroyeri, Heller 1862), adquirido no comércio de Niterói, foi transportado sob condições de refrigeração para a Embrapa Agroindústria de Alimentos e armazenado a $-18^{\circ} \mathrm{C}$ até sua utilização.

\subsection{MÉTODOS}

\subsubsection{Obtenção da farinha dos resíduos de camarão}

Os camarões foram descongelados, lavados e descascados 
manualmente. Os resíduos separados da carne do camarão foram inspecionados, lavados em água clorada (20 ppm) e submetidos à esterilização comercial $\left(121^{\circ} \mathrm{C}\right)$, em tacho encamisado, por 15 minutos. Os resíduos foram dispostos em bandejas para posterior secagem a $70{ }^{\circ} \mathrm{C}$ durante quatro horas. Após secagem, os resíduos desidratados foram desintegrados em moinho de facas e martelo, com peneira $0,50 \mathrm{~mm}$. Para total homogeneidade das partículas, a farinha foi peneirada durante 10 minutos, em conjunto de sete peneiras vibratórias, com abertura de malha variando de 5 a 35 mesh. O material desidratado na forma de farinha foi mantido em potes de vidro com capacidade para $5 \mathrm{~kg}$ e armazenado em ambiente seco, arejado e ao abrigo da luz.

\subsubsection{Análise de $\mathrm{N}$-total, lipídios, cinzas e fibra alimentar}

As análises de $\mathrm{N}$-total, lipídios, fibra alimentar e cinzas foram realizadas segundo a AOAC (1997).

\subsubsection{Extração e quantificação de proteína solúvel}

Para extração de proteína utilizaram-se $10 \mathrm{~g}$ de material e $50 \mathrm{~mL}$ de tampão fosfato $(20 \mathrm{mM})$. Desta maneira foram obtidos extratos contendo proteína solúvel dos resíduos de camarão in natura, de farinha de resíduos e de corpo de camarão. Antes da pesagem, os materiais frescos foram triturados em multiprocessador doméstico e homogeneizados em blender, durante 2 minutos. Estes extratos foram, posteriormente, utilizados para análise molecular em eletroforese (SDS-PAGE).

\subsubsection{Eletroforese em gel de poliacrilamida contendo dodecil sulfato de sódio (SDS-PAGE)}

A eletroforese (SDS-PAGE) foi realizada conforme LAEMMLI (1970), utilizando géis de $0,75 \mathrm{~mm}$ de espessura. O percentual de acrilamida foi de $5,00 \%$ no gel de aplicação e de $12,00 \%$ no gel de separação. A corrida foi realizada overnightem aparelho tipo Protean (Bio-Rad) e corrente de $8 \mathrm{~mA}$. Foram utilizadas proteínas padrões de alto peso molecular da "BioRad", que apresentaram os seguintes valores, em kDa: miosina-205,0; $\beta$-galactosidase-118,0; albumina de soro bovino-85,0 e ovalbumina-47,0. Os padrões contendo proteínas de faixa larga de peso molecular da "BioLabs" apresentaram os seguintes valores em kDa: $\beta$-galactosidase-175,0; paramiosina-83,0; glutamato desidrogenase-62,0; aldolase-47,5; triosefosfato isomerase-32,5; $\beta$-lactoglobulina-25,0 e lisozima-16,5. 


\subsubsection{Extração com $\mathrm{NaOH}$ e quantificação da proteína na farinha dos resíduos de camarão}

Para a quantificação de proteína total extraída de farinha de camarão foram utilizados $50 \mathrm{~mL}$ de solução extratora de $\mathrm{NaOH} 2 \mathrm{~N}$ e $10 \mathrm{~g}$ da amostra de farinha de resíduos. Após homogeneização em blender durante 2 minutos, a amostra foi colocada em estufa durante 30 minutos a $100^{\circ} \mathrm{Ce}$ depois centrifugada duas vezes a $1500 \mathrm{rpm}$, durante $10 \mathrm{~min}$. Quantificouse a proteína pelo método colorimétrico de BRADFORD (1976), também utilizado por $\mathrm{OH}$ et al. (2000) para análise de proteína em resíduo desidratado de camarão.

\section{RESULTADOS E DISCUSSÃO}

\subsection{CARACTERIZAÇÃO FÍSICO-QUÍMICA DO CAMARÃO E DA FARINHA DE SEUS RESÍDUOS}

De acordo com AUSTIN etal. (1981) o valor da composição nutricional da farinha de resíduos de camarão depende da quantidade do exoesqueleto. Este é composto principalmente de quitina, polissacarídio de $\mathrm{N}$-acetil glicosamina. Os resultados da composição físico-química da farinha de resíduos de camarão-sete-barbas (Xiphopenaeus kroyerı) e do corpo deste in natura (em base seca) encontram-se na Tabela 1. Transformando-se os valores de $\mathrm{N}$-total (combustão) em proteína (mediante fator de 6,25) foram encontrados valores de $\mathrm{N}$-combustão no corpo do camarão maiores do que na farinha de resíduos. Essas diferenças devem ser ainda maiores, pelo fato da $\mathrm{N}$-quitina também estar incluída nos dados de N-combustão. Comparando-se com dados da literatura, em relação a teores protéicos, os resultados descritos neste trabalho (multiplicando-se $\mathrm{N}$-combustão pelo fator 6,25) apresentaram-se semelhantes aos encontrados por FANIMO et al. (2000) e superiores aos descritos por GILDBERG e STENBERG (2001). Entretanto, FANIMO et al. (2000) relataram que o baixo valor nutricional (em proteína) da farinha dos resíduos de camarão em relação à de peixe deve-se à presença do alto teor de quitina. Tais autores não questionaram se os altos valores protéicos poderiam ser decorrentes de valores superestimados de proteína. Deve-se destacar que no valor de $\mathrm{N}$-combustão (Tabela 1) também está incluído o nitrogênio presente na molécula de quitina. $\mathrm{O}$ alto teor de fibra alimentar na farinha de resíduos, possivelmente, é representado pela quitina não digerível no processo de análise. Atualmente, estes resíduos são desperdiçados por falta de utilização por parte das indústrias de camarão em conserva. 


\section{TABELA 1 - COMPOSIÇÃO FÍSICO-QUÍMICA (BASE SECA) DE CAMARÃO SETE-BARBAS (Xiphopenaeus kroyeri) "IN NATURA" E NA FARINHA DE SEUS RESÍDUOS ${ }^{a}$}

\begin{tabular}{c|cc}
\hline & TEOR DOS COMPONENTES $(\%)$ \\
\cline { 2 - 2 } ANÁLISES FíSICO-QUímICAS & CAMARÃO “IN NATURA” & $\begin{array}{c}\text { FARINHA DERESÍDUOS } \\
\text { DE CAMARÃO }\end{array}$ \\
\hline N-total & & 6,83 \\
Lipídio & 12,73 & 2,66 \\
Cinzas & 6,07 & 38,29 \\
Fibra alimentar & 9,32 & 15,38 \\
\hline
\end{tabular}

a Valores expressos em base seca.

b Método da combustão.

Comparando os resultados de farinha de resíduos com os obtidos para o corpo de camarão verificou-se que, a farinha apresentou valores de cinzas 4,11 maiores do que os obtidos para o camarão. De acordo com WANG e HWANG (2001) a composição dos sais minerais consiste, principalmente, de carbonato de cálcio, seguido de fosfato, magnésio, sílica e enxofre. Este aumento de cinzas, principalmente, no que concerne ao mineral cálcio indica potencial diferencial desta farinha para utilização em dietas para fins especiais. ROSENFELD et al., em 1997, afirmaram que a farinha de resíduos de camarão eleva os níveis de minerais no sangue, porém, sua qualidade protéica é inferior à de peixe. Portanto, pode-se dizer que este resíduo se destaca em relação ao corpo do camarão no que concerne a dois diferentes nichos alimentares: nutricional mineral (cinzas) e dietético (fibra alimentar). Os valores de proteína, glicídios e lipídios, do corpo de camarão foram, respectivamente, 1,87; 4,19 e 2,28 vezes maiores do que os encontrados na farinha de casca. Ressalta-se, assim, a viabilidade do uso da farinha de casca de camarão em dietas alimentares com exigência de menor conteúdo lipídico.

\subsection{PROTEÍNA SOLÚVEL EXTRAÍDA DO CAMARÃO E SEUS RESÍDUOS}

Visando a obtenção de resultados quantitativos de proteína solúvel e futuro uso desses extratos para caracterização molecular em eletroforese dos resíduos in natura e sua farinha, as proteínas solúveis foram extraídas em tampão fosfato $(20 \mathrm{mM})$. Os valores quantitativos de solubilidade das proteínas presentes no resíduo de camarão constam da Tabela 2. 


\section{TABELA 2 - AVALIAÇÃO DO PERCENTUAL DE PROTEÍNA SOLÚVEL EXTRAÍDA DO CORPO DE CAMARÃO IN NATURA, DE SEUS RESÍDUOS IN NATURA E DE FARINHAa}

\begin{tabular}{cc}
\hline MATERIAL & \% DE PROTEINA SOLÚVEL EXTRAÍDA \\
\hline Resíduo fresco & 1,11 \\
Farinha de resíduo & 0,72 \\
Corpo de camarão & 19,30 \\
\hline
\end{tabular}

a Resultados foram obtidos tomando-se como base a massa seca da amostra utilizada.

Observou-se que a solubilidade é baixa e que, com tampão fosfato, obtevese um mínimo de extração de proteína solúvel de farinha de resíduos de 0,72\%. Como parâmetro comparativo, esse mesmo estudo foi realizado no corpo do camarão in natura, sendo verificada extração de $19,3 \%$. Os resultados para o corpo de camarão seguiram o mesmo protocolo de extração utilizado por HUANG et al. (1990) para caracterização de surimi de camarão. É importante ressaltar que este tampão é capaz de extrair somente as proteínas responsáveis pela manutenção celular (fração sarcoplasmática). De acordo com os resultados, descritos na Tabela 2, encontrou-se grande quantidade de proteína no corpo do camarão, em comparação com sua farinha de resíduos. Esses extratos solúveis foram úteis para posterior aplicação na análise molecular com eletroforese em gel de poliacrilamida.

\subsection{QUANTIFICAÇÃO DA PROTEÍNA EM FARINHA DE RESÍDUOS DE CAMARÃO, EXTRAÍDA COM NaOH}

Os baixos índices de proteína solúvel (obtidos com tampão fosfato) e a impossibilidade de utilização de valores de N-combustão para cálculos de proteína em farinha de resíduos de camarão exigiram busca de forma alternativa para a quantificação de proteína. Com este objetivo utilizou-se a mesma metodologia descrita por $\mathrm{OH}$ et al. (2000), que adaptaram a técnica de extração com $\mathrm{NaOH} 2 \mathrm{~N}$ para a extração de proteína e a quantificação por análise colorimétrica pelo método de BRADFORD (1976).

Observou-se valor de extração total de 7,46\% de proteína (base seca). Apesar destes baixos índices protéicos extraídos, convém considerar que a casca de camarão é altamente rica em quitina (WANG e HWANG, 2001; CHANG e TSAI, 1997; MEYERS et al., 1989) e que esse polímero poderia dificultar a lise celular e, conseqüentemente, a liberação de proteína. De acordo com RAGHUNATH et al. (1995) proteínas de baixo 
peso molecular não parecem ser muito afetadas pela secagem, exceto a $70{ }^{\circ} \mathrm{C}$. Deve-se lembrar também que o método de Bradford limita-se à detecção de cadeias polipeptídicas na faixa de peso molecular de 3000$5000 \mathrm{kDa}$.

\subsection{SDS-PAGE DO CAMARÃO E DE SEUS RESÍDUOS}

Utilizando-se a técnica de eletroforese conforme já descrito por KAISER e KRAUSE (1985), como ferramenta adequada para identificação de espécies animais foram caracterizadas as cadeias polipeptídicas presentes nos seguintes extratos: (tampão fosfato $20 \mathrm{mM}$ ) dos resíduos de camarão in natura, da farinha de resíduos de camarão e do corpo do camarão in natura (Figura 1, A, B e C). Observou-se uma cadeia polipeptídica de $74 \mathrm{kDa}$ fortemente corada, tanto para a casca fresca como para a farinha de resíduos de camarão. Entretanto, as três outras bandas fracamente coradas de 39, 38 e 33kDa somente foram observadas no extrato protéico obtido de resíduos in natura. O processamento térmico causou desnaturação protéica que impediu a solubilidade das proteínas compostas por estas três cadeias polipeptídicas. A alternativa de possível hidrólise deve ser descartada, pois antes do processo de desidratação a $70^{\circ} \mathrm{C}$ houve a etapa de esterilização comercial a $121^{\circ} \mathrm{C}$. Esta temperatura seria suficiente para inativar todas as possíveis proteases presentes nos resíduos in natura. Verificou-se que a cadeia polipeptídica de $74 \mathrm{kDa}$ constituiu bom marcador molecular da farinha de resíduos de camarão como modelo comparativo ao realizar o ensaio de eletroforese com extratos de camarão in natura. Observou-se uma variedade de cadeias polipeptídicas típica de matéria-prima rica em proteínas (Figura 1C). Outro fator que indica a presença de material rico em proteína é a forte coloração das cadeias polipeptídicas. Este fato pode ser verificado nas bandas encontradas nas faixas de peso molecular de 106, 79, 76, 63, 42 e 24kDa.

\section{CONCLUSÃO}

A farinha da casca do camarão quando comparada ao seu corpo mostrou:

- potencial em relação a dois nichos alimentares, ou seja, nutricional (alto teor mineral) e dietético (alto teor de fibra e baixo teor de lipídios); baixo teor protéico solúvel sob o ponto de vista de extração e quantificação pelo método colorimétrico;

baixa diversidade protéica considerando-se menor número de cadeias polipeptídicas reveladas em gel de SDS-PAGE; 
- a presença de uma banda comum de $74 \mathrm{kDa}$, resistente ao tratamento térmico, que pode ser utilizada como marcador de padrão de identidade molecular desta farinha.

\title{
FIGURA 1 - PERFIS DE SEPARAÇÃO ELETROFORÉTICA SDS-PAGE DOS RESÍDUOS DO CAMARÃO IN NATURA, DA FARINHA E DO CORPO IN NATURA - VALORES EM KDa
}

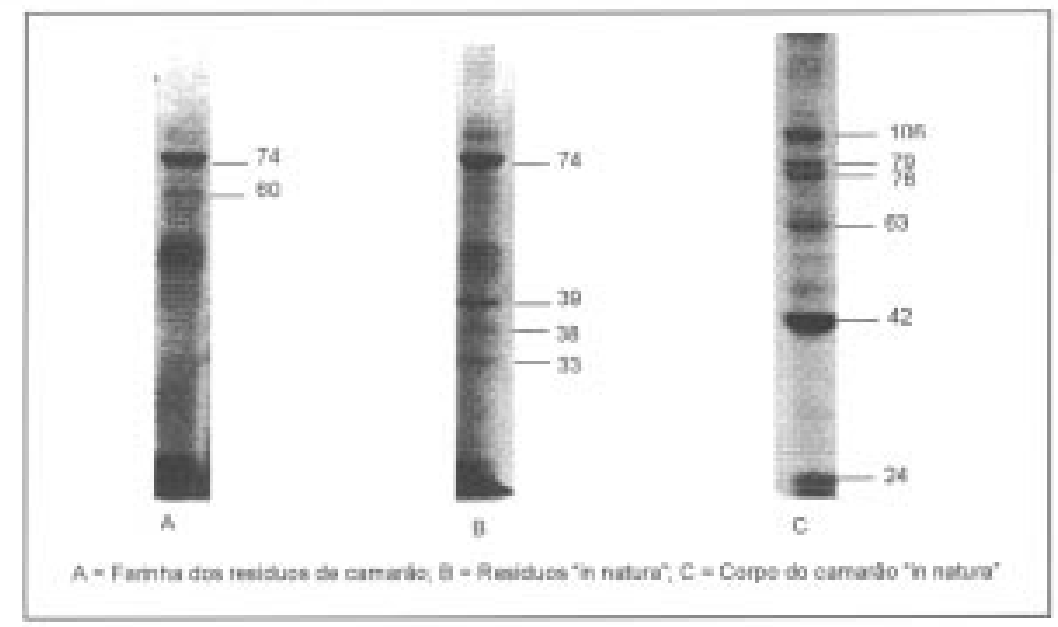

\begin{abstract}
CHEMICAL AND PROTEIC-MOLECULAR COMPOSITION OF SHRIMP "SETE BARBAS" RESIDUES FLOUR

The flour of shrimp "sete barbas" residues was characterized for physicochemical aspects and molecular analysis of proteins. The shrimp body was utilized as comparative parameter. Study of proteins was realized by the quantification of total $\mathrm{N}$, colorimetric analysis and molecular evaluation. The residues showed potential in relation to two alimentary niches: nutritional (mineral) and dietary (high levels of dietary fiber and low level of lipids). In this residue low amount of soluble protein was detected by colorimetric analysis. The extracts analysed by electrophoresis of SDS-PAGE showed a low diversity of protein, according to the low number of polypeptide chains identified. The presence of a band of $74 \mathrm{kDa}$, resistant to thermal treatment, may be utilized as a molecular marker to be a standard parameter to identify the shrimp flour.
\end{abstract}

KEY WORDS: SHRIMP-RESIDUE; FLOUR-SHRIMP; ELECTROPHORESIS. 


\section{REFERÊNCIAS}

1 AN, H.; MARSHALL, M.R.; OTWELL, W.S.; WEI, C.I. Species identification of raw and cooked shrimp by a urea isoeletric focusing technique. J. Food Sci., v. 54, p. 233-236, 1989.

2 AOAC. Association of Official Analytical Chemists. Official methods of analysis of AOAC International. $16^{\text {th }}$ ed. Gaitheersburg, 1997. Cap. 39, p. 6-7.

3 AUSTIN, P. R.; BRINE, C. J.; CASTLE, J. E.; ZUKAKIS, J. P. Chitin: new facets of research. Science, v. 212, p. 749-753, 1981.

4 BRADFORD, M. M. A rapid and sensitive method for quantitation of microgram quantities of protein utilizing principle of protein dye binding. Analytical Biochem., v. 72, p. 248-254, 1976.

5 CHANG, K. B.; TSAI, G. Response surface optimization and kinetics of isolation chitin from pink shrimp (Solenocera melantho) shell waste. J. Agric. Food Chem., v. 45, n. 5, p. 1900-1904, 1997.

6 CRAIG, A.; RITCHIE, A. H.; MACKIE, I. M. Determining the authenticity of raw reformed breaded scampi (Nephrops norvegicus) by eletrophoretic techniques. Food Chemistry, v. 52, n. 4, p. 343464, 1995.

7 EMOKPAE, A.O. Preliminary studies on the chemical and weight composition of some commercially important species of fish and shrimp caught in the Nigerian inshore waters. J. Food Technol., v. 18, n. 3, p. 271-283, 1983.

8 FANIMO, A. O.; ODUGUWA, O. O.; ONIFADE, A. O.; OLUTUNDE, T. O. Protein quality of shrimp waste meal. Bioresource Technology, v. 72, n. 2, p. 185-188, 2000.

9 FREITAS, J. V. F.; MACHADO, Z. L.; CHAVES, J. B. O.; GURGEL, J. J. S. Aproveitamento integral do camarão-canela (Macrobrachium amazonicus, Heller 1862) que ocorre nos açudes da Região Nordeste do Brasil. Recife: SUDENE, 1976. p. 45-52.

10 GILDBERG, A.; STENBERG, E. A new process for advanced 
utilization of shrimp waste. Process Biochemistry, v. 36, p. 809812, 2001.

11 HUANG, T.; CHEN, J. S.; MARSHALL, M. R.; WEI, C. Quantification of shrimp in shrimp-surimi mixtures using urea gel isoeletric focusing. J. of Food Sci., v. 5, n. 5, p. 1206-1209, 1990.

12 KAISER, K. P.; KRAUSE, I. Analytik von proteinem in Lebensmitteln mit elektrophoretischen und chromatographischen verfahren. $\mathbf{Z}$. Lebensm. Unters. Forsch., v. 180, p. 181-201, 1985.

13 LAEMMLI, U. K. Cleavage of structural proteins during the assembly of the head of bactiophage t4. Nature, v. 227, p. 680-685, 1970.

14 MEYERS, S. P.; NO, H. K.; LEE, K. S. Isolation and characterization of chitin from crawfish shell waste. J. Agric. Food Chem., v. 37, n. 3, p. 575-579, 1989.

15 OH, Y.S.; SHIH, I.L.; TZENG, Y.M.; WANG, S.L. Protease produced by Pseudomonas aeruginosa K-187 and its application in the deproteinization of shrimp and crab shell waste. Enzyme and Microbial Technology, v. 27, n. 1, p. 3-10, 2000.

16 RAGHUNATH, M.R.; SANKAR, T.V.; AMMU, K.; DEVADASAN, K. Biochemical and nutritional changes in fish proteins during drying. J. Sci. Food Agric., v. 67, n. 2, p. 197-204, 1995.

17 ROSENFELD, D. J.; GERNAT, A. G.; MARCANO, J. D.; MURILLO, J. G.; LOPEZ, G. H.; FLORES, J. A. The effect of using different levels of shrimp meal in broiler diets. Poult. Sci., v. 76, p. 581-587, 1997.

18 SHAHIDI, F.; SYNOWIECKI, J. Isolation and Characterization of Nutrients and Value-Added Products from Snow Crab (Chinoecetes opilio) and Shrimp (Pandalus borealis) Processing Discards. J. Agric. Food Chem., v. 39, n. 8, p. 1527-1532, 1991.

19 WANG, S.L.; HWANG, J.R. Microbial reclamation of shellfish waste for the production of chitinases. Enzyme and Microbial Technology, v. 28, p. 376-382, 2001. 